\title{
ESTIMATIVA DA VARIAÇÃO NA DEMANDA DE ÁGUA PARA IRRIGAÇÃO POR PIVÔ-CENTRAL NO DISTRITO FEDERAL ENTRE 1992 E 2002
}

\author{
EDSON E. SANO ${ }^{1}$, JORGE E. F. W. LIMA ${ }^{2}$, EUZEBIO M. SILVA ${ }^{3}$, ELAINE C. OLIVEIRA ${ }^{4}$
}

RESUMO: O aumento da demanda de água para a irrigação tem sido objeto de constante preocupação dos órgãos de gestão dos recursos hídricos e da população do Distrito Federal. Os objetivos deste trabalho foram determinar a variação da área irrigada por pivôs-centrais no Distrito Federal entre os anos de 1992 e 2002, estimar a demanda hídrica desses sistemas, bem como verificar sua importância em relação ao consumo humano. Utilizando imagens de satélite e ferramentas de geoprocessamento, foram determinadas as áreas irrigadas por pivô-central. O consumo de água dessas áreas irrigadas foi estimado com base em dados da literatura referentes às principais culturas semeadas na região. Entre 1992 e 2002, o número de pivôs-centrais no Distrito Federal passou de 55 para 104, a área irrigada de 3.894 ha para 6.823 ha e o consumo, de 23,36 para 40,94 milhões de $\mathrm{m}^{3}$ ano $^{-1}$. O consumo de água para irrigação por pivô-central no Distrito Federal é, ainda, menos representativo do que o consumo de água para o abastecimento humano; entretanto, a demanda para a irrigação tem crescido de forma mais acelerada, indicando tendência de alteração desse quadro.

PALAVRAS-CHAVE: agricultura irrigada, geoprocessamento, recursos hídricos.

\section{ESTIMATIVE VARIATION IN THE WATER DEMAND FOR IRRIGATION BY CENTER PIVOT IN DISTRITO FEDERAL - BRAZIL, BETWEEN 1992 AND 2002}

\begin{abstract}
The increase in the water demand for irrigation is a matter of concern of water resources management institutions and of the population from the Distrito Federal in Brazil. The objectives of this work were to determine the variation of the irrigated area by center pivot in the Brazilian Distrito Federal in the period between 1992 and 2002, in order to estimate the water demand by these systems of irrigation, as well as to verify its importance in relation to human consumption. Using satellite images and GIS tools, the center pivot irrigated areas were determined and the water consumption by the main irrigated crops in this region was estimated using reference data obtained from the literature. In the period between 1992 and 2002, the number of center pivots in the Distrito Federal increased from 55 to 104 and the corresponding irrigated area changed from 3.894 to $6.823 \mathrm{ha}$; consequently, the consumption of water increased from 23.36 to 40.94 million $\mathrm{m}^{3}$ year $^{-1}$. Although the demand of water for irrigation by center pivot in the Federal District is less representative than by human water consumption, the demand for irrigation has been growing in a higher rate, indicating a significant change in this trend.
\end{abstract}

KEYWORDS: irrigated agriculture, GIS, water resources.

\footnotetext{
${ }^{1}$ Geólogo, Pesquisador, Ph.D., Embrapa Cerrados, BR-020 km 18, Cx. Postal 08223, Planaltina - DF, Fone: (0XX61) 388.9874, sano@cpac.embrapa.br.

${ }^{2}$ Eng $^{\underline{0}}$ Agrícola, Pesquisador, Dr., Embrapa Cerrados, jorge @ cpac.embrapa.br.

${ }^{3}$ Eng $^{\mathrm{O}}$ Agrônomo, Pesquisador, Ph.D., Embrapa Cerrados, euzebio@cpac.embrapa.br.

${ }^{4}$ Geógrafa, B.S., Embrapa Cerrados, elainec@cpac.embrapa.br.

Recebido pelo Conselho Editorial em: 28-1-2004

Aprovado pelo Conselho Editorial em: 22-3-2005
} 


\section{INTRODUÇÃO}

O aumento da demanda de água para a irrigação tem sido objeto de constante preocupação dos órgãos de gestão dos recursos hídricos e da população do Distrito Federal, uma vez que essa unidade federativa apresenta baixo índice de disponibilidade hídrica por habitante por ano. Segundo LIMA (2000), o Distrito Federal possui, atualmente, disponibilidade hídrica de aproximadamente $1.400 \mathrm{~m}^{3}$ habitante ${ }^{-1}$ ano $^{-1}$, considerada baixa com base nas classificações das Nações Unidas (SHIKLOMANOV, 1997), do Banco Mundial (REBOUÇAS et al., 1999) e de BEEKMAN (1999), o que indica a possibilidade de futura ocorrência de conflitos pelo uso da água e a necessidade de gestão dos recursos hídricos existentes.

Para que seja possível uma adequada gestão desses recursos, o conhecimento sobre a oferta e a demanda hídrica é fundamental. Tratando-se da oferta, sua determinação é efetuada, normalmente, com base em dados hidrométricos e estudos hidrológicos e estatísticos que permitem estimar a disponibilidade hídrica associada à probabilidade de ocorrência em determinada localidade e época do ano. A menos que existam reservatórios (barragens) ao longo dos cursos d'água, os impactos das atividades antrópicas sobre a oferta hídrica de um dado local se processam, normalmente, de forma lenta e, dependendo da relação espacial entre a área antropizada e a dimensão do curso d'água, não chegam a ser perceptíveis. Entretanto, quando se refere à demanda por recursos hídricos, o desenvolvimento das atividades antrópicas tem influência direta sobre esses valores, que podem ser alterados abruptamente, com a simples introdução de uma nova indústria ou área irrigada na bacia. Esse fato fortalece a idéia de que estudos para o conhecimento da demanda por recursos hídricos devem ser atualizados com maior freqüência que os de disponibilidade hídrica. Nos locais onde o sistema de gestão de recursos hídricos já está devidamente implementado, a integração entre os sistemas de informações, de outorga e de cobrança permitirá a constante atualização dos dados de disponibilidade e demanda hídrica, o que ainda não é o caso do Distrito Federal.

Durante a década de 1990, a população do Distrito Federal aumentou cerca de 28\%, passando de 1.601.094 habitantes em 1991 para 2.051.146 em 2000 (IBGE, 2003). Esse rápido crescimento populacional, além de requerer maior quantidade de água para o consumo humano, gerou incremento na demanda de alimentos, incentivando o uso da irrigação, que é uma atividade de consumo intensivo de água. Cabe destacar que, nessa região, o período de maior demanda de água para a irrigação coincide com o de menor disponibilidade hídrica, de maio a setembro, o que amplia os riscos de ocorrência de conflitos pelo uso da água. Assim, o conhecimento sobre a quantidade de água captada para a irrigação, em cada época do ano e local, é essencial para a adequada gestão dos recursos hídricos no Distrito Federal. Uma forma de reduzir os custos, o trabalho e o tempo para o levantamento desses dados constitui-se no uso de imagens de satélite e ferramentas de geoprocessamento (MOREIRA, 2001; MENDES \& CIRILO, 2001).

Devido à facilidade operacional, à alta adaptabilidade a diferentes condições de solo e topografia e à pequena demanda por mão-de-obra, a prática da irrigação por meio de sistemas de pivô-central vem sendo amplamente utilizada na região Centro-Oeste do Brasil (SILVA \& AZEVEDO, 1998), o que também é percebido no Distrito Federal.

A característica circular das áreas irrigadas por pivô-central, cuja extensão varia, em geral, de 10 a 120 ha, permite a delimitação rápida e precisa desses equipamentos de irrigação nas imagens orbitais. Em princípio, os sistemas sensores que coletam dados multiespectrais com resoluções espaciais da ordem de algumas dezenas de metros, podem ser utilizados para a referida delimitação. Nesse grupo, incluem-se, por exemplo, os satélites LANDSAT (norte-americano, com o sensor ETM+ de resolução espacial de $30 \mathrm{~m}$ ), SPOT (francês, com o sensor HRV de resolução espacial de $20 \mathrm{~m}$ ) e o CBERS (sino-brasileiro, com o sensor CCD de resolução espacial de $20 \mathrm{~m}$ ). Maiores detalhes sobre esses satélites e sensores podem ser encontrados em MOREIRA (2001). 
Diante do exposto, como forma de gerar dados e informações que contribuam para a adequada gestão dos recursos hídricos do Distrito Federal, os objetivos deste trabalho foram determinar, via imagens orbitais, a variação da área irrigada por pivôs-centrais no Distrito Federal entre os anos de 1992 e 2002 e, em seguida, estimar a demanda hídrica desses sistemas, bem como verificar sua importância em relação ao consumo humano.

\section{MATERIAL E MÉTODOS}

A área de estudo foi o Distrito Federal, unidade federativa brasileira que ocupa $5.782,80 \mathrm{~km}^{2}$. Em termos climáticos, caracteriza-se por apresentar duas estações bem definidas: seis meses de estação seca, de maio a outubro, e seis meses de estação chuvosa, de novembro a abril. No período chuvoso, é comum a ocorrência de veranicos (ASSAD et al., 1993), aumentando os riscos de quebra das safras agrícolas e a importância dos sistemas irrigados na região.

As imagens orbitais utilizadas neste estudo foram duas cenas do satélite LANDSAT (órbita/ponto WRS 221/71) adquiridas pelo Instituto Nacional de Pesquisas Espaciais - INPE, nas seguintes datas de passagem: 21 de setembro de 1992 e 4 de maio de 2002. A imagem de 1992 foi adquirida pelo sistema sensor TM (Thematic Mapper) do LANDSAT 5, enquanto a de 2002 foi obtida pelo sensor ETM+ (Enhanced Thematic Mapper Plus) do LANDSAT 7.

A resolução temporal do LANDSAT é de 16 dias, e cada cena cobre área de $185 \mathrm{~km}$ x $185 \mathrm{~km}$ no terreno. Quanto à resolução espectral, o TM abrange sete bandas, seis delas nos comprimentos de onda correspondentes ao visível e aos infravermelhos próximo e médio, com resolução espacial de 30 $\mathrm{m}$; a outra banda situa-se no infravermelho termal e possui resolução espacial de $120 \mathrm{~m}$. O ETM+ possui, basicamente, as mesmas características espectrais, à exceção da inclusão de banda pancromática com resolução espacial de $15 \mathrm{~m}$ e melhoria na resolução da banda do infravermelho termal para $60 \mathrm{~m}$ (NASA, 2005).

Essas imagens foram inicialmente georreferenciadas no ENVI, aplicativo comercial de processamento digital de imagens de satélite, utilizando imagem do Distrito Federal obtida por meio do sensor ETM+ do satélite LANDSAT, de $1^{0}$ de setembro de 1999, previamente registrada e disponível no Laboratório de Biofísica Ambiental da Embrapa Cerrados. Em seguida, foi efetuado um recorte nas imagens para eliminar todos os pontos situados fora do Distrito Federal, isolando a área de interesse desse estudo. Sobre a imagem do Distrito Federal, realizou-se a identificação dos pivôscentrais existentes. Esses pivôs, discriminados nas imagens, foram enumerados seqüencialmente e, utilizando a ferramenta de traçado de figuras circulares do software ArcView, estimou-se a área específica de cada um deles.

Com base nas áreas irrigadas e em dados de consumo de água das principais culturas plantadas sob pivô-central no Distrito Federal, estimou-se o consumo total de água por esses sistemas em 1992 e 2002.

Para efeito de comparação entre o consumo de água para a irrigação por pivô-central e para o consumo humano, estimou-se a quantidade de água utilizada para o abastecimento da população na área de estudo. Esse cálculo foi efetuado com base na população total do Distrito Federal em 1992 e 2002 e em dados médios de demanda hídrica por habitante por ano.

\section{RESULTADOS E DISCUSSÃO}

Nas Figuras 1a e 1b, apresentam-se os mapas de localização dos pivôs-centrais no Distrito Federal, em 1992 e 2002, respectivamente. Da análise dos mapas, pode-se observar incremento no número de pivôs-centrais no Distrito Federal entre os anos de 1992 e 2002, passando de 55 para 104 sistemas instalados. É importante observar, principalmente na Figura 1b, a grande concentração de 
pivôs ao longo da Bacia do Rio Preto, o qual também é a principal área de produção agrícola do Distrito Federal, informação fundamental para a adequada gestão dos seus recursos hídricos.

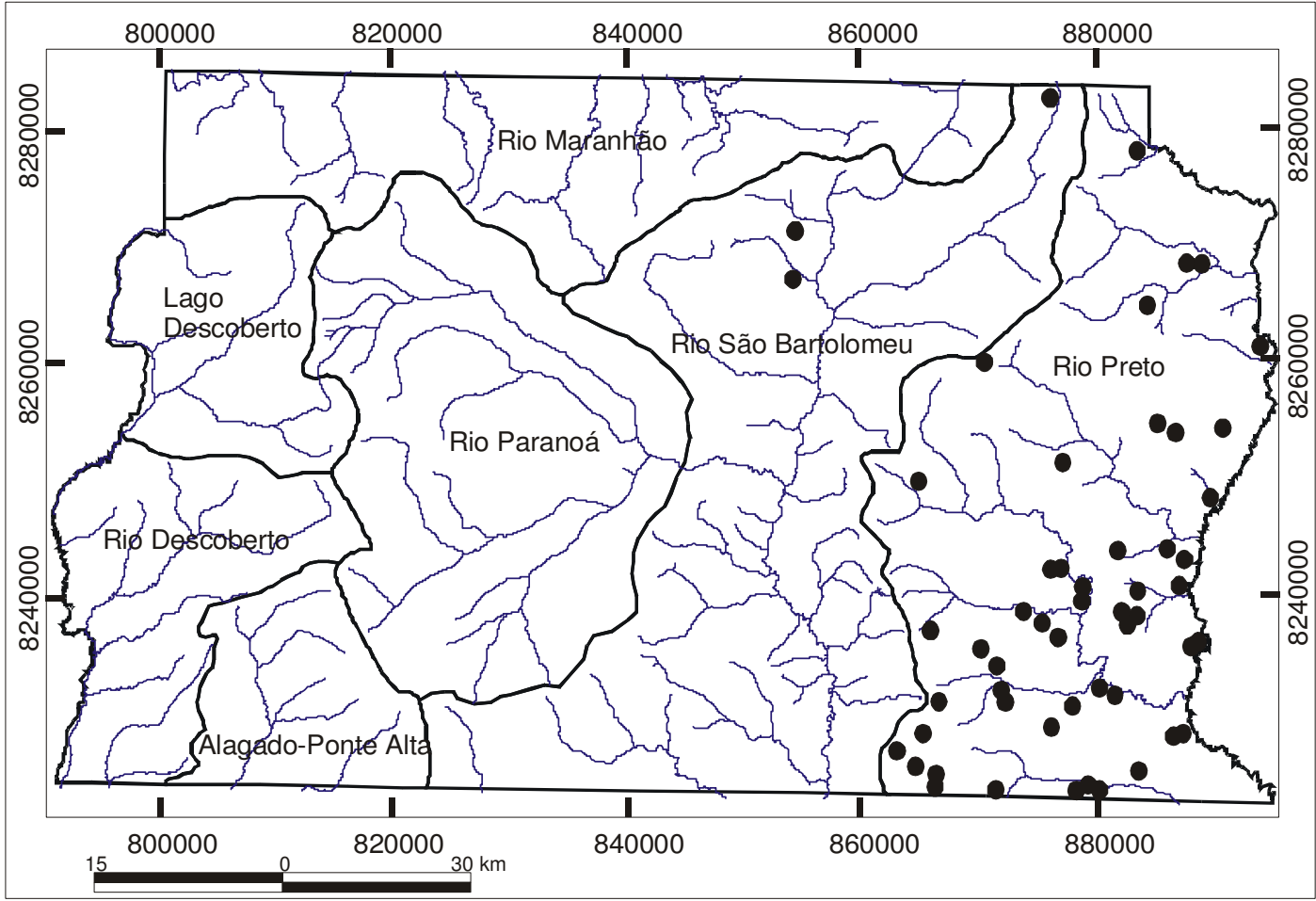

(a)

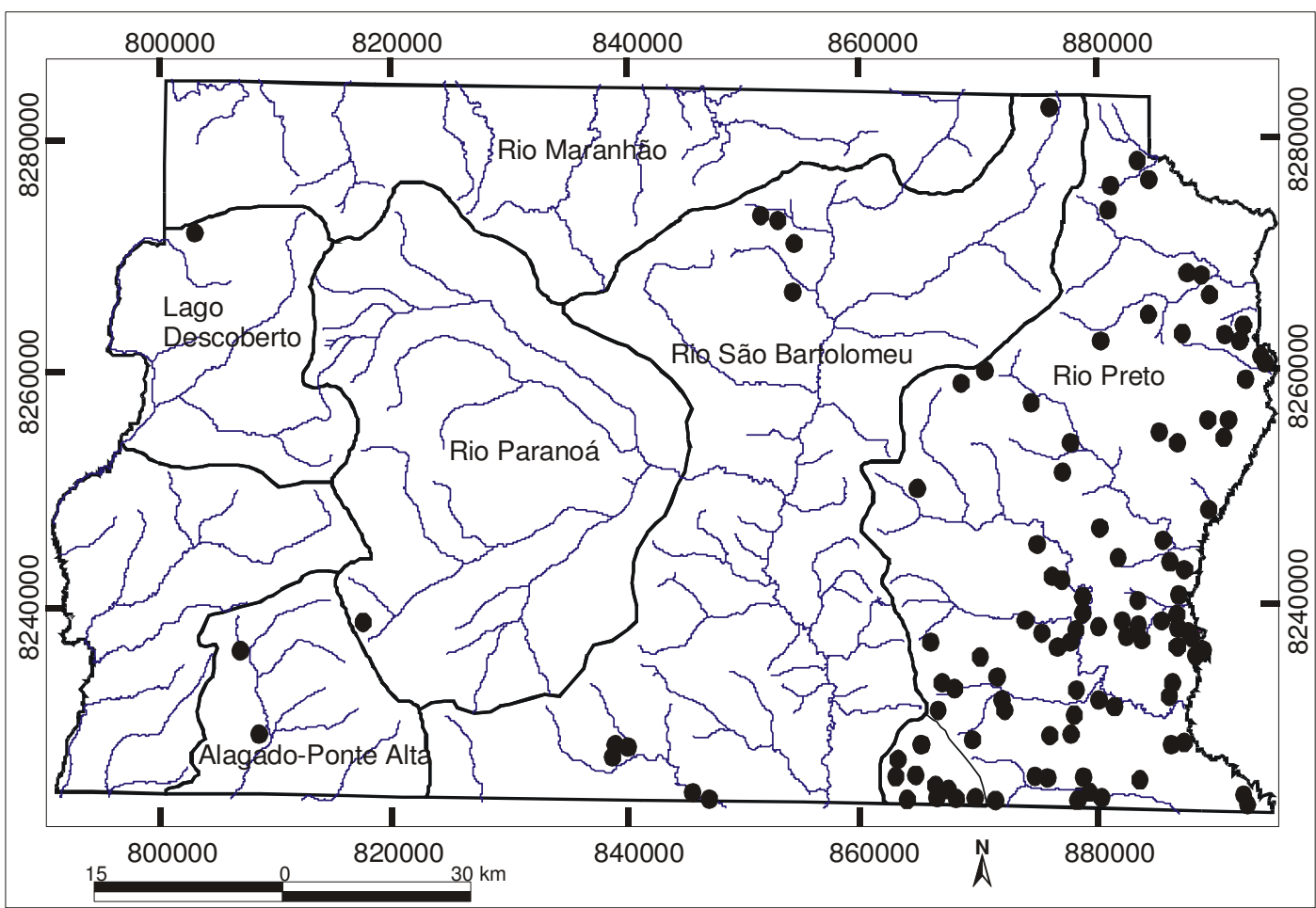

(b)

FIGURA 1. Mapa representativo dos pivôs-centrais instalados no Distrito Federal em 1992 (a) e 2002 (b). 
Na Tabela 1, apresenta-se o número de pivôs detectados nas imagens de 1992 e 2002, com as suas respectivas áreas correspondentes. Os 55 pivôs existentes em 1992 totalizavam área de 3.894 ha, dos quais 22 tinham área inferior a 60 ha, 23 entre 60 e 100 ha e 10 tinham área superior a 100 ha. A diferença de 49 pivôs instalados entre 1992 e 2002 representou acréscimo na área irrigada de 3.127 ha. Dessa forma, toda a área irrigada por pivô-central no Distrito Federal, em 2002, foi de 6.823 ha. Essa informação é coerente com os dados apresentados por CHRISTOFIDIS (2003), que registrou área irrigada por pivô-central na região, em 1997, da ordem de 6.256 ha, a qual representava 58,74\% da área total irrigada por aspersão (10.651 ha) e 55,68\% da área total irrigada no Distrito Federal (11.237 ha), considerando todos os métodos, inclusive o de pivô-central.

TABELA 1. Sistemas de irrigação por pivô-central identificados no Distrito Federal em 1992 e 2002.

\begin{tabular}{|c|c|c|c|c|c|c|c|}
\hline \multicolumn{4}{|c|}{ Pivô-central em 1992} & \multicolumn{4}{|c|}{ Pivô-central em 2002} \\
\hline Ordem & Área (ha) & Ordem & Área (ha) & Ordem & Área (ha) & Ordem & Área (ha) \\
\hline 1 & 6 & 29 & 81 & 56 & 9 & 84 & 69 \\
\hline 2 & 15 & 30 & 81 & 57 & 14 & 85 & 74 \\
\hline 3 & 15 & 31 & 81 & 58 & 14 & 86 & 74 \\
\hline 4 & 17 & 32 & 81 & 59 & 19 & 87 & 75 \\
\hline 5 & 20 & 33 & 81 & 60 & 21 & 88 & 78 \\
\hline 6 & 20 & 34 & 81 & 61 & 26 & 89 & 78 \\
\hline 7 & 31 & 35 & 81 & 62 & 30 & 90 & 81 \\
\hline 8 & 31 & 36 & 86 & 63 & 31 & 91 & 84 \\
\hline 9 & 31 & 37 & 86 & 64 & 32 & 92 & 86 \\
\hline 10 & 37 & 38 & 86 & 65 & 32 & 93 & 88 \\
\hline 11 & 40 & 39 & 91 & 66 & 35 & 94 & 92 \\
\hline 12 & 44 & 40 & 91 & 67 & 36 & 95 & 94 \\
\hline 13 & 44 & 41 & 91 & 68 & 36 & 96 & 96 \\
\hline 14 & 44 & 42 & 91 & 69 & 38 & 97 & 97 \\
\hline 15 & 44 & 43 & 96 & 70 & 38 & 98 & 99 \\
\hline 16 & 47 & 44 & 96 & 71 & 42 & 99 & 107 \\
\hline 17 & 51 & 45 & 96 & 72 & 42 & 100 & 121 \\
\hline 18 & 55 & 46 & 107 & 73 & 43 & 101 & 125 \\
\hline 19 & 55 & 47 & 107 & 74 & 46 & 102 & 128 \\
\hline 20 & 55 & 48 & 112 & 75 & 46 & 103 & 129 \\
\hline 21 & 59 & 49 & 113 & 76 & 52 & 104 & 132 \\
\hline 22 & 59 & 50 & 118 & 77 & 55 & & \\
\hline 23 & 61 & 51 & 118 & 78 & 60 & & \\
\hline 24 & 63 & 52 & 118 & 79 & 62 & & \\
\hline 25 & 72 & 53 & 124 & 80 & 63 & & \\
\hline 26 & 72 & 54 & 124 & 81 & 64 & & \\
\hline 27 & 76 & 55 & 136 & 82 & 66 & & \\
\hline 28 & 76 & & & 83 & 68 & & \\
\hline \multicolumn{4}{|c|}{ Área total em 1992: 3.894 ha. } & \multicolumn{4}{|c|}{ Área total em 2002: 3.127 ha. } \\
\hline
\end{tabular}

As principais culturas produzidas sob pivô-central no Distrito Federal são o feijão, o trigo, a cevada e o milho. AZEVEDO (1988) verificou que, na ausência de chuvas, podem ser necessários de 500 a $600 \mathrm{~mm}$ de água aplicada na cultura do trigo para a obtenção de safras entre 5.260 e $6.086 \mathrm{~kg} \mathrm{ha}^{-1}$, numa relação de aproximadamente $1 \mathrm{~kg}$ de grão por $\mathrm{m}^{3}$ de água aplicada. Em 118 hectares de trigo irrigado sob pivô-central, em Cristalina-GO, AZEVEDO (1997a) obteve $5.216 \mathrm{~kg} \mathrm{ha}^{-1} \mathrm{com} 451 \mathrm{~mm}$, registrando índice de cerca de 1,2 $\mathrm{kg}$ de grão por $\mathrm{m}^{3}$. Em lavoura de feijão, 
AZEVEDO et al. (1997b) obtiveram $3.445 \mathrm{~kg} \mathrm{ha}^{-1}$ com $336 \mathrm{~mm}$ de água aplicada ao longo do ciclo $\left(1 \mathrm{~kg} \mathrm{~m}^{-3}\right)$. No oeste baiano e em Unaí - MG, em solos arenosos, AZEVEDO et al. (1997c) e AZEVEDO et al. (1997d) produziram, com $392 \mathrm{~mm}$, respectivamente, 2.406 e $3.171 \mathrm{~kg} \mathrm{ha}^{-1}$ de feijão sob pivô-central $\left(0,6\right.$ e $\left.0,8 \mathrm{~kg} \mathrm{~m}^{-3}\right)$. Em 1994, durante o período seco, foram produzidos $5.801 \mathrm{~kg} \mathrm{ha}^{-1}$ de milho irrigado sob pivô-central, no Distrito Federal, utilizando-se de $577 \mathrm{~mm}$ de água, o que fornece uma conversão de $1 \mathrm{~kg} \mathrm{~m}^{-3}$. Para a cevada cervejeira, no Cerrado, FILGUEIRA et al. (1996) utilizaram $645 \mathrm{~mm}$ de água para produção de $5.416 \mathrm{~kg} \mathrm{ha}^{-1}\left(0,8 \mathrm{~kg} \mathrm{~m}^{-3}\right)$.

Baseados nesses valores, optou-se, neste trabalho, por utilizar o valor médio de demanda de água para a irrigação por pivô-central, no período seco do ano, como sendo de $500 \mathrm{~mm}$ por safra. Durante o período de chuva, essas áreas são, normalmente, cultivadas com soja ou milho, as quais, na eventualidade de ocorrência de veranicos, podem ser irrigadas de forma suplementar. Considerando a ocorrência de 20 dias de veranico, a demanda de água para a irrigação por pivô-central, nesse período, foi estimada em $100 \mathrm{~mm}$ por safra. Somando-se esses valores e fazendo-se as devidas conversões de unidades, tem-se que o índice médio de demanda de água para a irrigação por pivô-central no Distrito Federal é de $6.000 \mathrm{~m}^{3} \mathrm{ha}^{-1}$ ano $^{-1}$. Assim, em 1992, quando a área irrigada nesse sistema era igual a 3.894 ha, o consumo de água referente ao uso desses equipamentos foi estimado em 23,36 milhões de $\mathrm{m}^{3}$ por ano. Usando o mesmo índice de consumo, em 2002, os 6.823 ha irrigados por pivô-central demandaram cerca de 40,94 milhões de $\mathrm{m}^{3}$ por ano. Portanto, houve incremento de 17,58 milhões de $\mathrm{m}^{3}(75,3 \%)$ no consumo de água para a irrigação por pivô-central, no Distrito Federal, entre os anos de 1992 e 2002, o que representa taxa de crescimento anual de 5,77\%.

Tomando por base os dados fornecidos pela Companhia de Saneamento do Distrito Federal (CAESB), publicados pelo Serviço Nacional de Informações sobre Saneamento (SNIS, 2003) para o período de 1995-2001, o consumo médio de água diário per capita no Distrito Federal foi de 220,4 L. Sendo sua população, em 1992, estimada em 1.639.035 habitantes e, em 2002, em 2.145.839 habitantes (IBGE, 2003), pode-se deduzir que o volume de água correspondente ao consumo dessa população foi de 131,85 milhões de $\mathrm{m}^{3}$ em 1992, e de 172,62 milhões de $\mathrm{m}^{3}$ em 2002 . Nesse período de 10 anos, o aumento na demanda de água foi, portanto, de 30,9\%, correspondendo à taxa média de crescimento anual de 2,73\%. Dessa forma, pode-se concluir que, entre 1992 e 2002, o consumo de água para a irrigação por pivô-central, no Distrito Federal, cresceu em ritmo mais acelerado que para o abastecimento da população, o que foi comprovado pela diferença entre as taxas de crescimento anual desses usos durante o período analisado, de $5,77 \%$ e 2,73\%, respectivamente.

A análise do consumo de água para a irrigação, para ser completa, deve incluir todos os métodos de aplicação de água. Assim, considerando os dados da área irrigada pelos demais métodos de irrigação utilizados no Distrito Federal, apresentados por CHRISTOFIDIS (2003) para o ano de 1997, e assumindo que esses, diferentemente da irrigação por pivô-central, não tiveram as áreas expandidas entre 1997 e 2002, a área total irrigada no Distrito Federal em 2002 foi de aproximadamente 11.804 ha. Adotando o mesmo índice de consumo de água utilizado para os pivôs-centrais, de $6.000 \mathrm{~m}^{3} \mathrm{ha}^{-1} \mathrm{ano}^{-1}$, a demanda total de água para a irrigação, no Distrito Federal, em 2002, foi da ordem de 70,82 milhões de $\mathrm{m}^{3}$, o que representa cerca de $29,1 \%$ do total de água consumida para a irrigação e o consumo humano (243,44 milhões de $\mathrm{m}^{3}$ ). Desse total, 16,8\% (40,94 milhões de $\mathrm{m}^{3}$ ) foram utilizados para a irrigação por pivô-central. Esse resultado foi inferior ao apresentado por CHRISTOFIDIS (2003), que estimou em 65,8\% a relação entre a demanda de água para a irrigação, no Distrito Federal, e o consumo hídrico total. A diferença entre os resultados foi gerada pelo fato de CHRISTOFIDIS (2003) ter considerado a irrigação sendo conduzida durante todo o ano, o que não é correto, pois, na estação chuvosa, que vai de novembro a abril, dependendo da cultura, a irrigação só é utilizada durante os eventuais períodos de veranico. 
A disponibilidade hídrica superficial média do Distrito Federal foi estimada em $2,8 \mathrm{~km}^{3}$ ano ${ }^{-1}$ (REBOUÇAS et al., 1999). Portanto, em 2002, desse volume disponível, foram captados 1,5\% para a irrigação por pivô-central; 2,5\% para a irrigação por todos os sistemas e 6,2\% para o abastecimento humano, totalizando um índice de utilização de apenas $8,7 \%$ dos recursos hídricos superficiais disponíveis. Esse dado reflete uma distribuição eqüitativa da oferta e da demanda hídricas em todo o espaço geográfico estudado, podendo conduzir a uma idéia otimista quanto ao potencial de conflitos pelo uso da água no Distrito Federal. Entretanto, cabe ressaltar que a oferta e, principalmente, a demanda hídrica nessa região são distribuídas de forma bastante heterogênea no tempo e no espaço, o que amplia os riscos de ocorrência de problemas dessa natureza e a necessidade de gestão dos recursos hídricos.

\section{CONCLUSÕES}

No período de 1992 a 2002, houve aumento no número de equipamentos, na área irrigada e no consumo de água para irrigação por pivô-central, no Distrito Federal, sendo essa utilização dos recursos hídricos concentrada na Bacia do Rio Preto.

O consumo de água para irrigação por pivô-central, no Distrito Federal, é, ainda, menos representativo do que o consumo de água para o abastecimento humano; entretanto, a demanda para a irrigação tem crescido de forma mais acelerada, indicando tendência de alteração desse quadro.

\section{AGRADECIMENTOS}

Aos técnicos Heleno da Silva Bezerra e Lúcio Feitoza, da Embrapa Cerrados, pelo processamento das imagens de satélite utilizadas neste trabalho e ao CNPq, pela concessão da bolsa de produtividade em pesquisa ao primeiro autor.

\section{REFERÊNCIAS}

ASSAD, E.D.; SANO, E.E.; MASUTOMO, R.; CASTRO, L.H.R. de; SILVA, F.A.M. da. Veranicos na região dos cerrados brasileiros: freqüência e probabilidade de ocorrência. Pesquisa Agropecuária Brasileira, Brasília, v.28, n.9, p.993-1003, 1993.

AZEVEDO, J. A. Níveis de tensão de água no solo e suspensão da irrigação em três períodos de crescimento do trigo irrigado em solo de cerrado: efeito sobre a produtividade, componentes de produção, desenvolvimento e uso de água. 1988. 157 f. Tese (Doutorado em Solos e Nutrição de Plantas) - Escola Superior de Agricultura "Luiz de Queiroz”, Piracicaba, 1988.

AZEVEDO, J.A.; SILVA, D.B.; ANDRADE, J.M.V.; ANDRADE, L.M. Aplicação da tensiometria no manejo de água de irrigação em lavoura de trigo irrigado no Vale do Pamplona. Planaltina: EMBRAPA - Centro de Pesquisa Agropecuária dos Cerrados, 1997a. p.106-8. (Relatório Técnico Anual do Centro de Pesquisa Agropecuária dos Cerrados 1991-1995)

AZEVEDO, J.A.; DOLABELLA, R.H.C.; PEIXOTO, J.V.B.; SILVA, E.M. Manejo da irrigação usando-se tensiômetros e curva de retenção de água em feijão irrigado por aspersão. Planaltina: EMBRAPA - Centro de Pesquisa Agropecuária dos Cerrados, 1997b. p.102-4. (Relatório Técnico Anual do Centro de Pesquisa Agropecuária dos Cerrados 1991-1995)

AZEVEDO, J.A.; SILVA, E.M.; BREDA, C.E.; FIGUEREDO, S.F. Uso de tensiômetros e curva de retenção de água no manejo da irrigação do feijão em solo arenoso de Barreiras-BA. Planaltina: EMBRAPA - Centro de Pesquisa Agropecuária dos Cerrados, 1997c. p.112-14. (Relatório Técnico Anual do Centro de Pesquisa Agropecuária dos Cerrados 1991-1995) 
AZEVEDO, J.A.; SILVA, E.M.; SILVA, J.A.P.; FIGUEREDO, S.F. Manejo da irrigação usando tensiômetros em feijão sob pivô-central em solo de textura média de Unaí - MG. Planaltina:

EMBRAPA - Centro de Pesquisa Agropecuária dos Cerrados, 1997d. p.114-16. (Relatório Técnico Anual do Centro de Pesquisa Agropecuária dos Cerrados 1991-1995)

BEEKMAN, G.B. Gerenciamento integrado dos recursos hídricos. Brasília: IICA, 1999. 63 p. CHRISTOFIDIS, D. Os recursos hídricos para abastecimento humano, indústrias e irrigação no Distrito Federal. Disponível em: <http://www.ens.ufsc.br/ danieljs/irrigacao/textos/hidrico.doc>. Acesso em: 7 set. 2003.

FILGUEIRA, H.J.A.; GUERRA, A.F.; RAMOS, M.M. Parâmetros de manejo de irrigação e adubação nitrogenada para o cultivo de cevada cervejeira no Cerrado. Pesquisa Agropecuária Brasileira, Brasília, v.31, n.1, p.63-70, 1996.

IBGE. Censo demográfico de 1991 e 2000. Disponível: <http://www.ibge.gov.br>. Acesso em: 4 jun. 2003.

LIMA, J.E.F.W. Determinação e simulação da evapotranspiração de uma bacia hidrográfica do Cerrado. 2000. 75 f. Dissertação (Mestrado em Irrigação e Agroambientes) - Universidade de Brasília, Brasília, 2000.

MENDES, C.A.B.; CIRILO, J.A. Geoprocessamento em recursos hídricos: princípios, integração e aplicação. Porto Alegre: ABRH, 2001. 536 p.

MOREIRA, M.A. Fundamentos do sensoriamento remoto e metodologias de aplicação. São José dos Campos: INPE, 2001. 250 p.

NASA. Landsat 7. Disponível em: <http://geo.arc.nasa.gov/sge/landsat/17.html>. Acesso em: 16 fev. 2005.

REBOUÇAS, A.C.; BRAGA, B.; TUNDISI, J.G. Águas doces no Brasil: capital ecológico, uso e conservação. São Paulo: Escrituras, 1999. 717 p.

SHIKLOMANOV, I. A. (Ed.). Comprehensive assessment of the freshwater resources of the world: assessment of water resources and water availability in the world. Geneva: World Meteorological Organization, $1997.88 \mathrm{p}$.

SILVA, E.M.; AZEVEDO, J.A. Dimensionamento da lateral de irrigação do pivô-central. Planaltina: Embrapa-CPAC, 1998. 54 p. (Documentos, 71)

SNIS. Diagnóstico dos serviços de água e esgoto: série histórica 1995 a 2001. Disponível em: <http://www.snis.gov.br>. Acesso em: 5 set. 2003. 